\title{
Diversity of staphylococci exhibiting high-level resistance to mupirocin
}

\author{
MARY RAHMAN, SHAHRZAD CONNOLLY, W. C. NOBLE* B. COOKSONt‡ \\ and I. PHILLIPSt
}

Institute of Dermatology and TDepartment of Microbiology, United Medical and Dental Schools, St Thomas' Hospital, London SE1 7EH

Summary. Plasmids mediating high-level resistance to mupirocin (MIC $>1000 \mathrm{mg} /$

L) in staphylococci from various sources were studied by restriction endonuclease cleavage. Several patterns were obtained but six plasmids isolated from various Staphylococcus aureus and S. epidermidis strains were indistinguishable. The diversity and spread of these plasmids is illustrated.

\section{Introduction}

Mupirocin (Beecham, UK) is a topical antibiotic which acts by inhibiting isoleucyl-tRNA synthetase, a mechanism not employed by any other therapeutically available antibiotic. ${ }^{1}$ It is of value in the treatment of staphylococcal and streptococcal infection, in the suppression of nasal staphylococci, and in the management of eczematous and other lesions infected with Staphylococcus aureus.

In 1987 we reported high-level resistance to mupirocin in strains of $S$. aureus isolated from patients in dermatology wards. ${ }^{2,3} \mathrm{We}$ also drew attention to the difference in endonuclease cleavage patterns of genetic elements which mediated the conjugative transfer of mupirocin resistance. ${ }^{4} \mathrm{We}$ now report on the diversity of strains we have encountered.

\section{Materials and methods}

\section{Staphylococcal strains}

Strains of $S$. aureus resistant to $>1000 \mathrm{mg}$ of mupiro$\operatorname{cin} / \mathrm{L}$ were isolated in St Thomas' Hospital, London or sent to us from elsewhere. Details are given in table I. Additionally, we have screened 357 isolates of coagulasenegative staphylococci from patients receiving continuous ambulatory peritoneal dialysis (CAPD), 290 strains of $S$. aureus collected in 1964-1965 from random samples of a rural population in the Netherlands, 32 strains

Received 2 March 1990; accepted 9 April 1990.

* Correspondence should be sent to: Professor W. C. Noble, Institute of Dermatology, St Thomas' Hospital, London SE1 $7 \mathrm{EH}$.

$\ddagger$ Present address: Division of Hospital Infection, Central Public Health Laboratory, Colindale, London NW9 5HT. collected from a Nigerian population in 1965-1966 and 360 strains of various staphylococcal species isolated from pigs during a study of porcine exudative epidermitis during 1987-1989.

Coagulase-negative strains were identified by the API Staph system (API Products, Basingstoke).

\section{Examination of plasmid properties}

Conjugative transfer of plasmids to $S$. aureus strains NCTC 8325, B111 or RN 2677 made resistant to rifampicin $80 \mathrm{mg} / \mathrm{L}$, fusidic acid $30 \mathrm{mg} / \mathrm{L}$ or novobiocin $5 \mathrm{mg} / \mathrm{L}$, was performed on filters as described by Rahman et $a l .^{3}$ Plasmids or restriction-endonuclease fragments were separated on agarose gels with Escherichia coli V517 or phage $\lambda$ cut by HindIII (Gibco BRL) as standards. Endonuclease cleavage with EcoRI and HindIII (Gibco BRL) was done according to the maker's instructions.

Plasmids that co-migrated with the chromosomal DNA in both caesium chloride-ethidium bromide density gradients and in conventional agarose gels ${ }^{2,3}$ were demonstrated by pulsed field gel electrophoresis (PFGE) in the Pharmacia hexagonal array with agarose $1 \%$, at $170 \mathrm{~V}$ with a 5 -s pulse time for c. $20 \mathrm{~h}$. Plasmids not separable in caesium chloride density gradients were demonstrated as described elsewhere ${ }^{3}$ by cleaving wholecell DNA from a $S$. aureus NCTC 8325 or B111 recipient or by recovery of plasmid DNA by elution from PFGE gels.

\section{Results}

\section{Coagulase-positive staphylococci}

The two original epidemic strains from $\mathrm{St}$ Thomas' Hospital ${ }^{2,3}$ possessed an identical plasmid that mediated mupirocin resistance, here typified by strain J2385. All other strains from St Thomas' 
Table I. Sources and characteristics of mupirocin-resistant S. aureus

\begin{tabular}{|c|c|c|c|c|c|c|c|}
\hline \multirow{2}{*}{\multicolumn{2}{|c|}{$\begin{array}{c}\text { Source and year } \\
\text { of isolation }\end{array}$}} & \multirow[b]{2}{*}{$\begin{array}{l}\text { Domestic } \\
\text { code }\end{array}$} & \multirow[b]{2}{*}{$\begin{array}{l}\text { Resistance } \\
\text { pattern* }\end{array}$} & \multirow[b]{2}{*}{$\begin{array}{l}\text { Plasmid } \\
\text { profile } \dagger\end{array}$} & \multirow{2}{*}{$\begin{array}{l}\text { Transferability } \\
\text { of mupirocin } \\
\text { resistance }\end{array}$} & \multicolumn{2}{|c|}{ Plasmid DNA detected in } \\
\hline & & & & & & $\underset{\text { gradients }}{\mathrm{CsCl}}$ & $\begin{array}{l}\text { PFGE } \\
\text { gel }\end{array}$ \\
\hline 1 & STH 1987 & $\mathrm{~J} 2385$ & Pc Tc Em & $30,4 \cdot 2,3 \cdot 4,3 \cdot 1,2 \cdot 7,2 \cdot 2$ & ++ & - & + \\
\hline 2 & Glasgow 1987 & $\mathrm{~J} 2625$ & Pc Tc Em & $30,4 \cdot 2$ & ++ & - & + \\
\hline 3 & Bristol 1987 & $\mathrm{~J} 2627$ & $\mathrm{Pc}$ & $50,30,2 \cdot 9,2 \cdot 3$ & \pm & + & + \\
\hline 4 & STH 1988 & $\mathrm{~J} 2872$ & Pc & 35,20 & \pm & + & NT \\
\hline 5 & STH 1988 & $\mathrm{~J} 2870$ & $\mathrm{Pc}$ & 35,25 & + & + & + \\
\hline 6 & Warr 1988 & $\mathrm{~J} 2878$ & $\begin{array}{l}\text { Pc Tc Nm Em Cl } \\
\text { Gm Mt }\end{array}$ & $50,35,3 \cdot 5$ & ++ & - & + \\
\hline 7 & Warr 1988 & $\mathrm{~J} 2880$ & $\begin{array}{l}\mathrm{Pc} \mathrm{Tc} \mathrm{Nm} \mathrm{Em} \mathrm{Cl} \\
\mathrm{Gm} \mathrm{Mt}\end{array}$ & $35,3 \cdot 5$ & + & - & + \\
\hline 8 & STH 1989 & $\mathrm{~J} 2925$ & Pc Tc Nm Em & $30,2 \cdot 8$ & ++ & + & + \\
\hline 9 & STH 1989 & $\mathrm{~J} 2956$ & Sensitive & 35 & - & + & + \\
\hline 10 & STH 1989 & J3090 & Sensitive & 35 & - & + & NT \\
\hline 11 & Nigeria 1965 & DUT 471 & Pc & $20,15,6 \cdot 5$ & - & NK & NT \\
\hline 12 & Nigeria 1965 & DUT 473 & $\mathrm{Pc}$ & $20,15,6 \cdot 5$ & - & NK & NT \\
\hline 13 & Nigeria 1965 & DUT 476 & $\mathrm{Pc}$ & 25,20 & + & + & NT \\
\hline
\end{tabular}

NT, not tested; NK, not known; STH, St Thomas' Hospital (S. aureus J2385 is the original strain); Warr, Warrington.

* Pc, penicillin; Tc, tetracycline; Nm, neomycin; Em, erythromycin; Cl, clindamycin; Gm, gentamicin; Mt, methicillin. Only resistances are shown. All strains were resistant to mupirocin (MIC $>1000 \mathrm{mg} / \mathrm{L}$ ).

$\dagger$ Measured as intact plasmids on agarose gels $(\mathrm{kb})$.

Hospital were epidemiologically distinct. Strains from Warrington also formed part of an epidemic of infection; no other strain was associated with spread of infection or colonisation.

Some mupirocin resistance plasmids were readily transferable to $S$. aureus strain NCTC 8325 or B111 and are assumed to be conjugative plasmids (table I). In other instances, resistance did not transfer to $S$. aureus NCTC 8325 or B111 despite several attempts, but in a few cases transferred at a low frequency of $<10^{-8}$ to the restriction-deficient strain RN 2677.

Plasmids that co-migrated with chromosomal DNA, but which could be separated by PFGE, were isolated from the original St Thomas' Hospital $S$. aureus strain $\mathrm{J} 2385$ and the Glasgow $S$. aureus strain J2625. In all other cases an apparently closed circular DNA plasmid was demonstrated in conventional agarose gels and by ethidium bromidecaesium chloride density gradients.

No mupirocin-resistant strain was found among $S$. aureus isolated during 1964-1965 or among the staphylococci from pigs. Four strains resistant to mupirocin were found in the strains from Nigeria, one of which proved to be coagulase-negative (see below).

\section{Coagulase-negative staphylococci}

High-level resistance in coagulase-negative staphylococci was recorded from three sources (table II). Four isolates encountered in routine clinical specimens during or shortly after the $S$. aureus outbreak at St Thomas' Hospital were all $S$. epidermidis: three were also resistant to penicillin, tetracycline and erythromycin but had different plasmid profiles, and the remaining strain was resistant to penicillin and tetracycline as well as mupirocin. In two instances (S. epidermidis $\mathrm{J} 2516$ and $\mathbf{J} 2435$ ) mupirocin resistance was transferred to S. aureus NCTC 8325, and produced a conventional plasmid band on caesium chloride gradients.

Coagulase-negative staphylococci resistant to high levels of mupirocin were isolated from nine of 18 patients who were undergoing CAPD; of 357 isolates from these 18 patients, 26 were resistant. The true number of unrelated strains is not known. Five patients yielded resistant $S$. epidermidis strains, two $S$. capitis, one $S$. hominis and one $S$. haemolyticus. All strains transferred mupirocin resistance to $S$. aureus NCTC 8325 or B111 but conventional plasmids could not be demonstrated in these transferants by electrophoresis. However, with one exception, separate plasmid bands were seen by PFGE. Restriction patterns obtained for transferants from three of these isolates were different.

One Nigerian strain ( $S$. epidermidis DUT 451) differed from the three $S$. aureus strains in being sensitive to penicillin. Mupirocin resistance was transferable to $S$. aureus NCTC 8325 . 
Table II. Sources and characteristics of mupirocin-resistant coagulase-negative staphylococci

\begin{tabular}{|c|c|c|c|c|c|c|c|}
\hline & $\begin{array}{c}\text { Source and year } \\
\text { of isolation }\end{array}$ & Identity & $\begin{array}{l}\text { Domestic } \\
\text { code }\end{array}$ & $\begin{array}{l}\text { Resistance } \\
\text { pattern }\end{array}$ & $\begin{array}{l}\text { Plasmid } \\
\text { profile }\end{array}$ & Transferability & $\begin{array}{c}\text { Plasmid DNA } \\
\text { detected on } \\
\mathrm{CsCl} \text { gradient }\end{array}$ \\
\hline 14 & STH 1987 & S. epidermidis & $\mathrm{J} 2516$ & Pc Tc Em & $30,25,5 \cdot 9,5 \cdot 0,2 \cdot 9$ & \pm & + \\
\hline 15 & STH 1987 & S. epidermidis & $\mathrm{J} 2518$ & Pc Tc Em & $35,4 \cdot 2,2 \cdot 9$ & - & NK \\
\hline 16 & STH 1987 & S. epidermidis & $\mathrm{J} 2435$ & Pc Tc Em & $30,6 \cdot 5,4 \cdot 0,2 \cdot 6$ & \pm & + \\
\hline 17 & STH 1987 & S. epidermidis & J2869 & $\mathrm{PcTc}$ & None seen & - & + \\
\hline 18 & Nigeria 1965 & S. epidermidis & DUT 451 & Sensitive & $25,3 \cdot 2,2 \cdot 5$ & + & + \\
\hline 19 & GH 1987 & S. hominis & VIA & Sensitive & None seen & + & - \\
\hline 20 & GH 1987 & S. epidermidis & $\mathrm{A} 14 \mathrm{C}$ & Pc Tc Em & None seen & + & - \\
\hline 21 & GH 1987 & S. capitis & BY8H & Sensitive & $5 \cdot 8,5 \cdot 3,2 \cdot 6,1 \cdot 7$ & + & - \\
\hline
\end{tabular}

GH, Guy's Hospital. Other abbreviations as for table I.

\section{Restriction patterns}

Restriction patterns of most of the plasmids transferred to standard strains were different (table III). However, the plasmids from $S$. aureus strains $\mathrm{J} 2872$, J3090 and $\mathrm{J} 2880$, and those from $S$. epidermidis strains DUT 451, J2516 and J2435 had indistinguishable EcoRI and HindIII digest patterns. There were marked similarities between the patterns from this group of six indistinguishable plasmids (table III, column 7) and those from $S$. aureus strains J2878 and J2956 (table III, columns
6 and 9) which differed in the size of some bands; this was confirmed by electrophoresis of the cleaved DNA in adjacent lanes of a gel.

\section{Discussion}

A diversity of plasmids was encountered in this study. After double digestion with EcoRI and HindIII several common bands were visualised, but these were not universal and could be related to other plasmid functions. However, since the plas-

Table III. EcoRI restriction fragments of some mupirocin resistance plasmids

\begin{tabular}{|c|c|c|c|c|c|c|c|c|c|c|c|c|}
\hline & \multicolumn{12}{|c|}{ Fragment sizes $(\mathbf{k b})$ for plasmid from strain number* } \\
\hline & 1 & 2 & 3 & 5 & 6 & 7 & 8 & 9 & 13 & 19 & 20 & 21 \\
\hline & $>15$ & 14 & 15 & 5.9 & 15 & 13 & $7 \cdot 9$ & 12 & 13 & $9 \cdot 3$ & $11 \cdot 5$ & c. 25 \\
\hline & 13.7 & 13 & $9 \cdot 3$ & $5 \cdot 2$ & 13 & 6.6 & $5 \cdot 8$ & 8.4 & $8 \cdot 4$ & $7 \cdot 2$ & $7 \cdot 4$ & 15 \\
\hline & 11 & 10.6 & $7 \cdot 7$ & $4 \cdot 1$ & $5 \cdot 9$ & 5.7 & $4 \cdot 9$ & $5 \cdot 5$ & 4.0 & $6 \cdot 2$ & $6 \cdot 4$ & 13 \\
\hline & 4.0 & 6.8 & $6 \cdot 5$ & $2 \cdot 5$ & $4 \cdot 1$ & $4 \cdot 2$ & $3 \cdot 4$ & 3.9 & $2 \cdot 4$ & $5 \cdot 4$ & 5.0 & $8 \cdot 7$ \\
\hline & $3 \cdot 5$ & $5 \cdot 4$ & 3.9 & $2 \cdot 4$ & $2 \cdot 3$ & $2 \cdot 2$ & $2 \cdot 6$ & $2 \cdot 4$ & $2 \cdot 2$ & $4 \cdot 0$ & $4 \cdot 7$ & 3.4 \\
\hline & $2 \cdot 8$ & $5 \cdot 0$ & $(2 \cdot 9)$ & $1 \cdot 8$ & $2 \cdot 1$ & $2 \cdot 1$ & $1 \cdot 8$ & $2 \cdot 1$ & & $3 \cdot 7$ & $3 \cdot 9$ & 2.9 \\
\hline & $2 \cdot 7$ & $4 \cdot 5$ & $2 \cdot 4$ & 1.4 & $1 \cdot 7$ & $1 \cdot 7$ & & 1.7 & & 3.0 & $3 \cdot 1$ & 2.7 \\
\hline & $2 \cdot 4$ & $4 \cdot 2$ & $2 \cdot 2$ & & & & & & & 2.9 & & $2 \cdot 5$ \\
\hline & $1 \cdot 7$ & $3 \cdot 8$ & $1 \cdot 4$ & & & & & & & $2 \cdot 6$ & & 1.8 \\
\hline & & $3 \cdot 3$ & & & & & & & & & & \\
\hline & & $2 \cdot 6$ & & & & & & & & & & \\
\hline & & $2 \cdot 3$ & & & & & & & & & & \\
\hline & & $2 \cdot 1$ & & & & & & & & & & \\
\hline & & 1.8 & & & & & & & & & & \\
\hline & & $(1 \cdot 7)$ & & & & & & & & & & \\
\hline & & 1.5 & & & & & & & & & & \\
\hline & & $1 \cdot 2$ & & & & & & & & & & \\
\hline & & 1.0 & & & & & & & & & & \\
\hline Number of patterns & & & & & & & & & & & & \\
\hline analysed & 6 & 4 & 3 & 2 & 3 & 6 & 3 & 3 & 1 & 1 & 1 & 1 \\
\hline Total size (kb) & 57 & 87 & 52 & 23 & 29 & 36 & 26 & 36 & 30 & 44 & 42 & 75 \\
\hline
\end{tabular}


mids showed diversity when first recognised in 1965 , diversity in recent strains is to be anticipated. In contrast, the similarity of some plasmids, e.g., in $S$. aureus strains $\mathrm{J} 2872, \mathrm{~J} 2880, \mathrm{~J} 3090$, and $S$. epidermidis strains DUT 451, J2516 and J2435, as shown by EcoRI and HindIII digests, shows their wide spread. The existence of resistance plasmids 20 years before commercial introduction of the antibiotic should not be surprising; mupirocin is a naturally-occurring product of Pseudomonas fluorescens and exposure of staphylococci under natural circumstances can be assumed.

Low-level mupirocin resistance, with minimal inhibitory concentrations $\leqslant 50-100 \mathrm{mg} / \mathrm{L}$, can be achieved by training staphylococci in vitro ${ }^{5}$ and such low-level resistance occurs naturally in vivo in strains not described here. The relationship, if any, between low and high resistance must remain speculative.

\section{REFERENCES}

1. Baines PJ, Jackson D, Mellows G, Swaisland AJ, Tasker TCG. Mupirocin: its chemistry and metabolism. In: Wilkinson DS, Price JD (eds) Mupirocin, a novel topical antibiotic. International congress and symposium series no. 80. London, Royal Society of Medicine. 1984: 13-22.

2. Rahman M, Noble WC, Cookson B. Mupirocin-resistant Staphylococcus aureus. Lancet 1987; 2: 387.

3. Rahman M, Noble WC, Cookson B. Transmissible mupirocin
Several of the plasmids described here cannot be demonstrated on caesium chloride density gradients or by conventional gel electrophoresis. This might indicate an open-circular or perhaps linear plasmid co-migrating with the chromosomal DNA, since plasmid DNA could be demonstrated by PFGE. These plasmids do not migrate at the same rate as conventional plasmids in PFGE but are proportionately faster than their size would suggest (data not shown). The genes, if any, that mediate this phenomenon are unknown but appear to be independent of the $\mathrm{tra}^{+}$genes presumed to be present on the conjugative plasmids, since not all plasmids that appear to be conjugative show the phenomenon.

We are grateful to Dr D. Baird, Glasgow, Professor D. Speller, Bristol and Dr R. Garvey, Warrington for sending us the strains, and to Beecham Pharmaceutical Research for partial financial support.

resistance in Staphylococcus aureus. Epidemiol Infect 1989; 102: 261-270.

4. Noble WC, Rahman M, Cookson B, Phillips I. Transferable mupirocin-resistance. J Antimicrob Chemother 1988; 22: 771-772.

5. White AR, Beale AS, Boon RJ et al. Antibacterial activity of mupirocin. In: Dobson RL, Leydon JJ, Noble WC, Price JD (eds) Bactroban (Mupirocin), Proceedings of an international symposium. (Current Clinical Practice Series 16), Amsterdam, Excerpta Medica. 1985: 19-36. 